
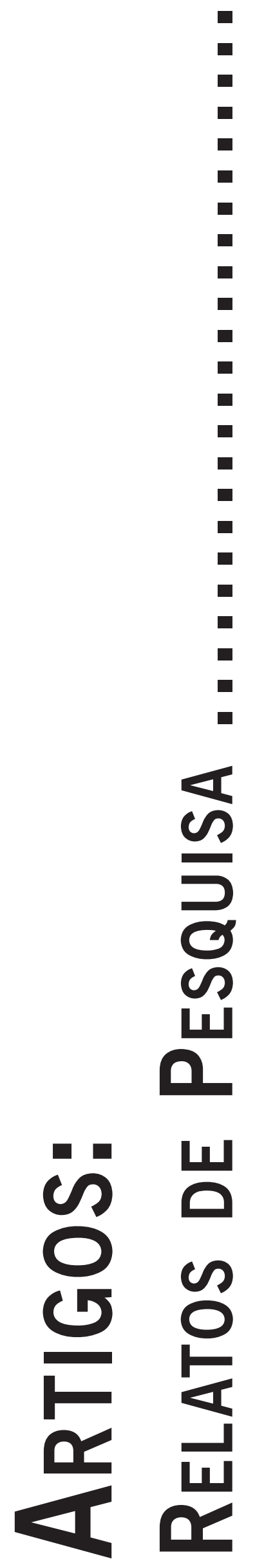


\title{
VARIÁVEIS ASSOCIADAS AO SENTIDO DE VIDA
}

\author{
Variables Associated With the Meaning of Life \\ Variables Relacionadas al Sentido de la Vida
}

\author{
Ana Paula Porto Noronha \\ DianNIFFER APARECIDA DE OliveIRA \\ LEONARDO DE Oliveira BARRos \\ THALINE Da CunHa Moreira
}

\begin{abstract}
Resumo: Considerando que o sentido de vida independe de situações de prazer e de realização e que é possível obtê-lo ainda que exista um sofrimento, o presente estudo teve como objetivo averiguar o que está associado ao sentido de vida dos brasileiros. Os participantes da pesquisa foram 901 pessoas, sendo 81,9\% do sexo feminino, com idades variando entre 18 e 77 anos e oriundos de 25 estados brasileiros. Para levantar tais informações foi desenvolvido um questionário, sendo respondido de forma online em um período de 10 dias no mês de julho de 2016, com questões como:em que você deposita sua energia e para que ou quem você dedica sua vida. Foram realizadas análises quantitativas e qualitativas. Nos resultados foi possível observar que a maioria das pessoas citaram a Família como o fator mais importante, além de associá-la ao sentido de vida e a quem dedicam a mesma. Além disso, houve diferença entre homens e mulheres quanto à palavra associada ao sentido de vida, de modo que as mulheres relacionam à família e o homem a missão e razão de viver. Os resultados são discutidos com base na literatura.
\end{abstract}

Palavras-chave: religiosidade; logoterapia; existencialismo

\begin{abstract}
Considering that the meaning of life is independent of situations of pleasure and accomplishment and that it is possible to obtain it even if there is suffering, the present study aimed to ascertain what is associated with the meaning of life of Brazilians. The participants of the survey were 901 people, $81.9 \%$ female, with ages varying between 18 and 77 years and coming from 25 Brazilian states. To raise this information, a questionnaire was developed,being answered online in a period of 10 days in July 2016, with questions such as: where you put your energy and what or who you dedicate your life to. Quantitative and qualitative analyzes were performed. In the results, it was possible to observe that most people cited the Family as the most important factor, besides associating it with the meaning of life and to those who dedicate it. Moreover, there was a difference between men and women as to the word associated with the meaning of life, so that women relate to family and man the mission and reason to live. The results are discussed on the basis of literature.
\end{abstract}

Keywords: religiosity; logotherapy; existentialism

Resumen: Considerando que el sentido de la vida es independiente de las situaciones de placer y logro y lo puede conseguir incluso si hay sufrimiento, este estudio tuvo como objetivo averiguar lo que está asociado com el sentido de la vida de los brasileños. Los participantes fueron 901 personas, 81,9\% mujeres, com edades comprendidas entre los 18 y los 77 años y oriundos de 25 estados brasileños. Para obtener esta información, hemos desarrollado um cuestionario, siendo respondido de forma online y nun período de 10 días en el mes de julio de 2016, con preguntas como: donde poner su energía y por qué o de quiénle dedica su vida. Se realizaronanálisiscuantitativos y cualitativos. Em los resultados se observó que lamayoría de las personas citaronfamilia como elfactor más importante, y com el sentido de la vida y los que participan enella. Además, no hubo diferencias entre hombres y mujeres y la palabra asociada com el sentido de la vida, por lo que las mujeres se relacionan com la familia y el hombre la misión y razón de vivir. Los resultados se discutenen base a la literatura.

Palavras-clave: religiosidad; logoterapia; existencialismo

\section{Introdução}

Na primeira metade do século XX, Viktor Frankl elaborou uma teoria cujo pressuposto se baseava que ter um sentido de vida (SV) poderia ser ao mesmo tempo um fator de proteção às adversidades, assim como contribuir para um sentido existencial (Ortiz \& Morales, 2013). O SV tem sido entendido, por exemplo, como um indicador de proteção ao suicídio. Um estudo longitudinal realizado por Kleiman, Adams, Kashdan e Riskind (2013) com estudantes universitários revelou que a gratidão confere resistência ao suicídio, aumentando o sentido de vida.
A temática foi objeto de estudo da Logoterapia, tendo sido o psiquiatra austríaco Frankl seu principal idealizador. A abordagem se baseia no pressuposto de que o ser humano está em incessante busca de sentido e, considera o homem com estrutura para sua realização (Frankl, 1984). O sentido de vida é acessível à pessoa, independentemente de sua condição e não há algo que seja universal, pois eles são individuais e transitórios, dependendo, assim, intrinsicamente do momento em que ele se faz presente (Frankl, 1989; Pereira, 2014).

A pessoa se autorrealiza em busca de um sentido à medida que essencialmente "esquece de si mesmo" e de- 
dica-se a algo maior (Frankl, 1993), como por exemplo, trabalhos que proporcionem ajudar ao próximo, no qual os benefícios não são voltados unicamente para um ou outro e, sim, para o meio social. Quando o indivíduo compreende seus padrões pessoais, torna-se capaz de distanciar-se de si mesmo. Dessa forma, pode tomar partido e escolher o que fazer, para depois agir (Frankl, 1989).

Para uma vida com sentido, três valores são considerados relevantes, sendo eles, valor criativo, valor vivencial e valor atitudinal. $\mathrm{O}$ primeiro refere-se à execução de uma boa ação. Valor vivencial trata das experiências da pessoa com o mundo. Por fim, valor atitudinal, diz respeito aos padrões pessoais de reações, ou seja, o quanto as pessoas aprendem e se desenvolvem diante de situações difíceis (Frankl, 1998). Segundo Frankl (1989) a ausência de um sentido vital pode levar o sujeito a apresentar sintomas como ansiedade e depressão. Para o autor, o sentido existencial precisa ser encontrado e não criado.

O significado de SV também foi discutido por Allport (1954) e Maslow (1962). No entanto, os autores não tinham a intenção de mensurá-lo, o que ocorreu mais recentemente (Schnell \& Becker, 2006). Nos últimos anos o tema tem recebido atenção de pesquisadores e amostras distintas foram investigadas, sendo que estudosrelacionando SV com características positivas têm sido alvo de algumas pesquisas (Steger, Frazier, Oishi, \& Kaler, 2006).

Pinquart (2002) realizou uma meta-análise com base em 70 estudos sobre o propósito de vida em pessoas com idades a partir de 60 anos. Os achados indicaram um declínio no propósito de vida à medida que a idade avança. Foram encontrados níveis mais elevados de propósito naqueles com maiores índices de saúde, melhor integração social, nos casados e com nível socioeconômico mais elevado. As diferenças quanto ao sexo foram pequenas, o que foi reforçado por Ortiz e Morales (2013), no sentido de que os apontamentos quanto ao gênero são controversos.

No que se refere aos estudos de sentido de vida com professores, Damasio, Melo e Silva (2013) avaliaram os índices de SV, de bem-estar psicológico e de qualidade de vida em docentes de escolas públicas e privadas, com vistas a compreender se o SV modera a relação entre os outros dois construtos. Os resultados revelaram que o SV é variável preditora de bem-estar psicológico e de qualidade de vida.

Foram investigados por Oliveira e Silva (2013) os principais elementos psicossociais que favorecem bons níveis de saúde mental ou bem-estar psicológico e a factível relação entre estes. Participaram da pesquisa 146 pessoas de cinco cidades do estado de Sergipe com idade média de 68,9 anos, sendo a maioria do sexo feminino (65\%). Os resultados sugeriram uma relação positiva entre as variáveis SV e bem-estar psicológico, sendo que ambos se mostraram relevantes fatores protetivos para depressão.

Ademais, o SV e sua relação com as variáveis otimismo, esperança, satisfação com a vida, felicidade subjetiva, autoestima e autoeficácia foi verificada em uma amostra de 3.034 sujeitos, sendo 63,9\% mulheres, com idades variando entre 18 e 91 anos, provenientes de 22 estados do Brasil. Os resultados indicaram que a busca pelo SV foi maior entre os que apresentam conflito existencial (Damásio, 2013). A avaliação do bem-estar e do SV em processos terapêuticos podem promover o desenvolvimento saudável do cliente e, em outra medida, Pinquart (2002) endossou a forte correlação negativa com a depressão. O otimismo serve como mediadorda relação entre SV e afetos positivos e negativos (Ho, Cheung, \& Cheung, 2010); o que também foi verificado no estudo de Doğan, Sapmaz, Tel, Sapmaz e Temizel, (2012), no qual o poder preditivo de SV em relação ao bem-estar subjetivo foi de $34 \%$.

A adaptabilidade de carreira, mais especialmente a preocupação e o controle com a carreira, também é predita pelo SV (Yuen \& Yau, 2015). Os fatores que motivam o SV de jovens universitários foram pesquisados por Claussen e Soto (2015) e os achados sugeriram que há relação com expectativas futuras, nos quais os valores foram subjetivos e carregados de experiências daquela geração.

Pesquisas transculturais têm contribuído para um melhor entendimento do tema, entretanto os estudos ainda precisam ser aprofundados (Sommerhalder, 2010). Embora os achados encontrados ofereçam subsídios para analisar as fases do adulto e da velhice, Sommerhalder (2010) realizou um levantamento bibliográfico exploratório a fim de verificar as definições de SV. Os resultados revelaram que o construto é definido como um fator importante para a saúde e considerado novo na área de estudos do envelhecimento, no qual é relacionado a menores chances de adoecer. Ainda, enfatiza a continuidade da busca de SV ao longo da trajetória dos indivíduos.

O SV tem sido compreendido como uma percepção de organização, coesão, ou lógica, frente à própria existência, em conjunto com a busca e satisfação de metas significativas ao indivíduo, o que proporciona um sentimento de realização existencial (Damasio, Melo, \& Silva, 2013). Tal construto tem uma dimensão individual, como também é considerado um elemento cultural. Isto é, as experiências de vida, ainda que sejam singulares, fazem parte da cultura na qual a pessoa está inserida, e isso afeta as decisões pessoais, ou seja, estes podem realizar escolhas com base em opiniões, valores e metas coletivas (Sommerhalder, 2010). Ainda, segundo a autora, não basta a pessoa estar inserida no contexto social, é importante sentir-se parte da cultura para que seu sentido de vida seja compartilhado pela sociedade. Por fim, o SV é definido como um construto multidimensional, tal como afirmado por Halama (2009) e Ortiz, Cano e Trujillo (2012).

Considerando as definições e os estudos que vêm sendo realizados a respeito do SV, principalmente os brasileiros, que indicam o quanto a presença e a busca de um sentido pode ser protetivo e importante para a saúde ao longo da vida das pessoas (Sommerhalder, 2010; Oliveira \& Silva, 2013; Damásio, 2013), é que se problematiza o presente estudo, com vistas ao entendimento de quais 
são os elementos mais associados ao SV em uma amostra brasileira. Para tanto, foi desenvolvido especificamente para esta pesquisa um questionário para conhecer como as pessoas estão considerando o sentido existencial delas. A elaboração desta ferramenta se deu com base na logoterapia e as postulações de Victor Frankl a respeito da busca e existência de um sentido de vida.

\section{Objetivos}

O presente estudo tem por objetivo investigar quais fatores e temas os brasileiros associam a sentido de vida e verificar diferenças em funções das variáveis sexo, escolaridade, situação trabalhista e prática da religião.

\section{Método}

\section{Participantes}

Participaram da pesquisa 901 pessoas, dos quais 738 $(81,9 \%)$ eram do sexo feminino e $163(18,1 \%)$ do masculino, com idades variando entre 18 e 77 anos, sendo a média de 35,19 anos $(D P=11,9)$. Entre os homens, a idade variou de 18 a $68(M=33,58, D P=11,880)$ e entre as mulheres variou de 18 a $77(M=35,54, D P=11,928)$. No que diz respeito à escolaridade, do sexo masculino, participaram mais pessoas com ensino superior (39,3\%), embora a diferença para aqueles com pós-graduação tenha sido pequena $(34,4 \%)$. No entanto, para mulheres, a maior parte tinha pós-graduação $(48,6 \%)$, vindo em seguida, as participantes com ensino superior $(36,4 \%)$. Os participantes eram provenientes de 24 estados brasileiros, com a maior concentração no estado de São Paulo (41,5\%) e Minas Gerais $(17,2 \%)$, o que também aconteceu para os homens, embora com porcentagens menores em ambos os estados $(35,4 \%$ e $14,1 \%)$

Também se buscou conhecer a atribuição religiosa dos participantes, sendo que dos participantes homens, a maior parte se declarou católico $(44,8 \%)$, vindo em seguida os que afirmaram não ter uma religião $(11,7 \%)$ e os espíritas (8\%). As demais religiões mencionadas tiveram menos de $7 \%$ de endosso. No que concerne às participantes do sexo feminino, a maior parte se declarou católica $(51,4 \%)$, vindo em seguida as que afirmaram não ter uma religião $(12,2 \%)$, as espíritas $(11,5 \%)$ e as protestantes $(8,1 \%)$. As demais religiões tiveram menos de $5 \%$ de endosso.

\section{Instrumentos}

O questionário desenvolvido pelos pesquisadores do presente estudo buscou conhecer como as pessoas consideram o seu sentido existencial. Para tanto, foram levan- tadas questões sociodemográficas, como idade, sexo, unidade de federação, escolaridade, se trabalhavam ou não e religião. Para atender ao objetivo da pesquisa as seguintes questões foram elaboradas, "em que você tem depositado sua energia ultimamente”, "para que ou quem você dedica sua vida", "quando eu digo para você sentido de vida, qual a primeira palavra que você pensa imediatamente". As perguntas eram abertas, sem limite de caracteres para o tamanho da resposta.

\section{Procedimentos}

O estudo em questão está inserido em um projeto de pesquisa mais amplo, que foi devidamente apreciado e recebeu parecer favorável do Comitê de Ética em Pesquisa da Universidade São Francisco, CAAE: 20410713.3.0000.5514. A coleta foi realizada de forma online, sendo disponibilizado o link nas redes sociais por meio da plataforma do Google Drive, por um período de 10 dias durante o mês de junho de 2016. A primeira parte do questionário foi destinada a explicar os objetivos da pesquisa e o tempo de resposta necessário para completá-la, sendo que os participantes levaram em média 10 minutos para responder ao protocolo. Após concordarem com o Termo de Consentimento Livre e Esclarecido (TCLE), os participantes tinham acesso ao questionário.

\section{Procedimentos de análise dos dados}

Esta pesquisa contou com análises quantitativas e qualitativas. Assim, inicialmente os dados foram organizados por meio do programa estatístico SPSS v.20, tendo sido realizadas análises descritivas para a caracterização da amostra. Em seguida, foram empregadas análises de conteúdo para as perguntas do questionário, com o intuito de formar categorias de respostas. As categorias foram construídas com base nos pressupostos de Bardin (2004), assim para cada pergunta as respostas foram agrupadas de acordo com a temática a que elas pertenciam. Para a primeira pergunta (o que você considera mais importante na sua vida) as categorias definidas foram: família, trabalho, deus/fé, saúde, amor, amigos, paz, financeiro, felicidade, eu em relação à minha vida, liberdade e respostas múltiplas.

Na categoria 'família' foram incluídas as respostas que citavam pai, mãe, filhos e marido. Entendeu-se como 'trabalho’ aquelas ideias voltadas à profissão, experiência, realização e sucesso profissional. Jesus, espírito, espiritualidade foram incluídas na categoria 'deus/fé'. Na categoria ‘amigos' foram considerados argumentos relacionados à companheirismo e coleguismo. Calma, harmonia e tranquilidade integraram a categoria 'paz'. No 'financeiro' foram inseridas palavras como dinheiro, economia, sucesso financeiro. Felicidade, alegria e bem-estar se agruparam; e 
'eu em relação à minha vida' pode ser ilustrado com termos como evolução pessoal, aprendizado e sacrifício. Não foram encontrados sinônimos para as categorias, 'saúde', 'amor' e ‘liberdade'. Por fim, na categoria 'respostas múltiplas' ficaram agrupadas aquelas que eram compostas por várias categorias, como por exemplo, saúde, paz e família; ou profissão e família.

Em relação à segunda questão (quando eu digo a você sentido de vida o que vem imediatamente a sua cabeça?), as categorias da primeira pergunta se mantiveram, excetuando-se financeiro e eu em relação à vida e foram incluídas estudo, viver, propósito, sonho, missão, evolução, caridade, razão de viver, sabedoria, realização, universo, generosidade, futuro e prosperidade. As palavras geraram categorias, de modo que nesta questão totalizaram 30 .

Por fim, a última questão (para quem você dedica a vida?) gerou dez categorias de análise. Na categoria 'família' foram incluídos os termos filhos, esposos, namorados, pais, amores, avós, sobrinhos, animais e outros relativos às relações familiares. Sociedade, humanidade, ao próximo são as ideias que resumem a categoria 'para o outro'. Em 'realização' foram incluídos os termos felicidade, ser feliz, vida e valores. A categoria 'família e outros' considerou a família e trabalho, ou estudo, ou lazer, ou amigos. Ainda, a 'família' apareceu em outra categoria, mas voltada à religião. 'Para si' também configurou uma categoria de análise, tendo como exemplos: satisfação própria; para mim e minha família; para mim e deus. A 'religião' configurou-se como uma categoria, na qual foram incluídas as palavras deus, cristo, Jesus, espiritualidade e igreja. Estudo, trabalho, profissão e conhecimento compuseram a categoria 'trabalho/estudo', enquanto ‘evolução'incluiu ser uma pessoa melhor, evolução do mundo, missão de vida, futuro, sonho, realização. Por fim, criou-se a categoria "sem denominação" que incluiu respostas como "não sabe, ninguém, pessoa sem denominação, busca de algo, céu”. As categorias foram organizadas consensualmente por duplas de autores.

Após a análise qualitativa, empregaram-se análises estatísticas para comparação das médias dos participantes nas variáveis sexo, escolaridade, situação trabalhista e prática da religião. Utilizou-se teste t de Student, Análise de variância (ANOVA) e Prova de Tukey com o intuito de verificar diferenças estatisticamente significativas entre os grupos.

\section{Resultados}

Inicialmente foram analisadas as frequências das respostas para o que as pessoas consideram mais importante em suas vidas, seguido da palavra associada a sentido de vida e para quem ou o que a vida é dedicada. A Tabela 1 apresenta a frequência para o que as pessoas consideram como mais importante, sendo que dos 901 participantes da pesquisa, 49 deixaram essa questão em branco. A categoria 'família' obteve maior frequência com $38,4 \%$ das respostas, seguido de 'respostas múltiplas' (24,6\%). Todas as demais categorias tiveram frequências menores do que $10 \%$ em cada, sendo que a menor porcentagem $(0,6 \%)$ foi para as pessoas que consideraram as questões financeiras como o mais importante.

Tabela 1: Frequência das respostas à pergunta "O que você considera mais importante em sua vida"

\begin{tabular}{lcc}
\hline \multicolumn{1}{c}{ Categorias } & F & \% \\
\hline Família / Filhos / Marido & 327 & 38,4 \\
Respostas múltiplas & 210 & 24,6 \\
Deus / Fé & 54 & 6,3 \\
Felicidade /Bem-estar / Qualidade de vida & 49 & 5,8 \\
Saúde & 41 & 4,8 \\
Liberdade / Sinceridade / Respeito & 38 & 4,5 \\
Amigos / Amizades Relacionamentos & 34 & 4,0 \\
Amor & 26 & 3,1 \\
Eu / Vida & 24 & 2,8 \\
Paz / Tranquilidade & 23 & 2,7 \\
Trabalho /Profissão / Carreira / Sucesso profissional & 21 & 2,5 \\
Financeiro & 5 & 0,6 \\
\hline Total & $\mathbf{8 5 2}$ & $\mathbf{1 0 0}$ \\
\hline
\end{tabular}

Em relação a palavra associada ao sentido de vida, não houve respostas ausentes, sendo que da amostra total, 19,8\% dos participantes endossaram 'família' em primeira posição. Com maiores frequências também estiveram as categorias formadas por palavras associadas a 'amor' $(16,1 \%)$ e ‘deus' $(16,1 \%)$. De modo semelhante à primeira pergunta, todas as demais categorias tiveram menos que $10 \%$ dos participantes em cada com menores frequências para as categorias 'estudo', 'liberdade' e 'futuro' com $0,4 \%$ em cada. Os resultados dessa análise podem ser vistos na Tabela 2. 
Tabela 2: Frequência das palavras associadas à sentido de vida

\begin{tabular}{|c|c|c|}
\hline Categorias & $\mathbf{F}$ & $\%$ \\
\hline Família, Pais, Cônjuge, Filhos & 178 & 19,8 \\
\hline Amor, Amar, Afeto, Sentir & 145 & 16,1 \\
\hline Deus, Jesus, Allah & 138 & 15,3 \\
\hline Felicidade, Alegria, Contentamento & 86 & 9,9 \\
\hline Propósito, Objetivo, Meta, Direção, Rumo, Caminho & 41 & 4,6 \\
\hline Viver, Vida, Respirar & 37 & 4,1 \\
\hline Fé, Espiritualidade, Espírito, Religião, Salvação, Santidade & 30 & 3,3 \\
\hline Saúde, Ser saudável & 29 & 3,2 \\
\hline Razão de viver, Sentido, Busca, Motivo, Autodesenvolvimento & 23 & 2,6 \\
\hline Realização, Auto realização, Motivação, Satisfação, Prazer & 20 & 2,2 \\
\hline Evolução, Evoluir, Aprimoramento, Plenitude, Crescimento & 19 & 2,1 \\
\hline Trabalho, Profissão, Carreira, Serviço & 16 & 1,8 \\
\hline Paz, Paz de espírito, Paz interior & 16 & 1,8 \\
\hline Missão, Vocação & 14 & 1,6 \\
\hline Harmonia, Equilíbrio, Bem-estar, Sintonia, Estabilidade & 14 & 1,6 \\
\hline Caridade, Solidariedade, Ajudar, Empatia, Compaixão, Fraternidade & 12 & 1,3 \\
\hline Sabedoria, Aprendizado, Conhecimento, Reflexão & 12 & 1,3 \\
\hline Generosidade, Dignidade, Respeito, Verdade, Tolerância, Sinceridade & 12 & 1,3 \\
\hline Prosperidade, Intensidade, Força, Dedicação, Momento & 9 & 1,0 \\
\hline Amigos, Amizade & 7 & 0,8 \\
\hline Sonho & 7 & 0,8 \\
\hline Ter com quem contar, Relacionamentos, Outras pessoas & 7 & 0,8 \\
\hline Vazio, Morte, Solidão, Perdida, Sofrimento, Dor, Não tem sentido & 7 & 0,8 \\
\hline Universo, Cosmos, Sociedade, Natureza & 6 & 0,7 \\
\hline Estudo, Estudar, Formação & 4 & 0,4 \\
\hline Liberdade & 4 & 0,4 \\
\hline Futuro, Destino, Nascer & 4 & 0,4 \\
\hline Total & 901 & 100 \\
\hline
\end{tabular}

Por fim, foram analisadas as frequências para a pergunta "para que ou quem você dedica sua vida", sendo que das dez categorias formadas, a 'família' também aparece com maior frequência de respondentes, representando $37,2 \%$, seguidos dos que dedicam a vida a si próprias $(22,1 \%)$ e para a 'religião' $(11,1 \%)$. As demais categorias reuniram $5,4 \%$ ou menos em cada, com menor frequência para as pessoas que dedicam a vida a realizar algo $(2,4 \%)$. Os dados podem ser visualizados na Tabela 3.

Tabela 3: Frequência das respostas à pergunta "Para que ou quem você dedica sua vida”

\begin{tabular}{lcc}
\hline \multicolumn{1}{c}{ Categorias } & F & \% \\
\hline Família & 335 & 37,2 \\
Para si & 199 & 22,1 \\
Religião & 100 & 11,1 \\
Ao outro & 49 & 5,4 \\
Evolução & 48 & 5,3 \\
Família e outros & 44 & 4,9 \\
Família, religião, trabalho/estudo & 44 & 4,9 \\
Trabalho e Estudo & 32 & 3,6 \\
Sem denominação & 28 & 3,1 \\
Realização & 22 & 2,4 \\
\hline Total & $\mathbf{9 0 1}$ & $\mathbf{1 0 0 , 0}$ \\
\hline
\end{tabular}

Após a análise de frequência, foram utilizadas estatísticas inferenciais com o intuito de verificar diferenças nas respostas em função da pessoa estar trabalhando ou não, do sexo, de praticar a religião e do nível de escolaridade. Para isso as respostas dos participantes às três perguntas foram recodificadas utilizando os valores 1para presente e 0 para ausente. Foram considerados para o relato apenas os resultados com significância estatística.

Em relação ao que é considerado mais importante na vida (primeira questão), a variável situação de trabalho não se mostrou significativa. Todavia, foram encontradas diferenças significativas entre os sexos, sendo que os homens obtiveram maiores médias em 'trabalho', 'paz' e 'liberdade', enquanto as mulheres consideram a 'família' como o mais importante. Para os níveis de escolaridade, apenas a categoria 'deus/fé' revelou diferenças significativas $(p<0,001)$, na qual pessoas com Pós-Graduação obtiveram as menores médias e os participantes com Ensino Médio formaram um subconjunto com maiores pontuações. Quando as respostas foram comparadas em função da pessoa praticar a religião, encontraram-se diferenças significativas para 'família', 'deus/fé', 'respostas múltiplas' e 'felicidade', tal como pode ser visto na Tabela 4. 
Tabela 4: Análise de variância e Tukey para o que as pessoas consideram mais importante na vida e prática da religião

\begin{tabular}{|c|c|c|c|c|c|c|}
\hline \multirow{2}{*}{ Variável } & \multirow{2}{*}{ gl } & \multirow{2}{*}{ F } & \multirow{2}{*}{$p$} & \multirow{2}{*}{ Prática da religião } & \multicolumn{2}{|c|}{ Subconjuntos } \\
\hline & & & & & 1 & 2 \\
\hline \multirow{3}{*}{ Família } & 2 & 3,336 & $0,03^{*}$ & Não se aplica & 0,28 & \\
\hline & & & & Sim & & 0,40 \\
\hline & & & & Não & & 0,41 \\
\hline \multirow{3}{*}{ Deus/Fé } & 2 & 16,811 & $<0,01^{* *}$ & Não & 0,00 & \\
\hline & & & & Não se aplica & 0,01 & \\
\hline & & & & Sim & & 0,10 \\
\hline \multirow{3}{*}{ Respostas Múltiplas } & 2 & 6,090 & $<0,01^{* *}$ & Não & 0,21 & \\
\hline & & & & Sim & 0,23 & \\
\hline & & & & Não se aplica & & 0,37 \\
\hline \multirow[t]{3}{*}{ Felicidade } & 2 & 5,122 & $<0,01^{* *}$ & Sim & 0,04 & \\
\hline & & & & Não se aplica & 0,06 & 0,06 \\
\hline & & & & Não & & 0,10 \\
\hline
\end{tabular}

* Significativo a nível de $\mathrm{p}<0,05$ ** Significativo a nível de $\mathrm{p}<0,001$.

A partir da análise da primeira palavra associada a sentido de vida (segunda questão) foi possível constatar que as mulheres associam este construto diretamente à 'família' enquanto os homens o entendem como missão, razão de viver ou como algo relacionado a dedicar-se ao 'estudo'. Quando as respostas foram comparadas de acordo com a situação trabalhista, verificou-se que as pessoas que não trabalharam diferenciaram-se significativamente das que estão ativas no mercado de trabalho, entendendo sentido de vida como praticar caridade e como algo a ser conquistado ainda, evidenciado pela categoria'futuro'.
A análise de variância de acordo com o nível de escolaridade gerou diferenças significativas nas médias das respostas. Os participantes pós-graduados apresentaram o ‘amor' como a palavra mais associada a sentido de vida quando comparados com pessoas com Ensino Superior e Ensino Médio, sendo que estes últimos também formaram subconjuntos na Prova de Tukey entendendo a Caridade como sentido de vida. Investigou-se também se a prática da religião diferenciaria as categorias, sendo que foram significativas para 'família', 'deus', 'felicidade', 'missão' e 'futuro', como pode ser visto na Tabela 5.

Tabela 5: Análise de variância e Tukey para a palavra associada a sentido de vida e prática da religião

\begin{tabular}{|c|c|c|c|c|c|c|}
\hline \multirow{2}{*}{ Variável } & \multirow{2}{*}{ gl } & \multirow{2}{*}{$\mathbf{F}$} & \multirow{2}{*}{$p$} & \multirow{2}{*}{ Prática da religião } & \multicolumn{2}{|c|}{ Subconjuntos } \\
\hline & & & & & 1 & 2 \\
\hline \multirow[t]{3}{*}{ Família } & 2 & 4,538 & $0,01^{*}$ & Não se aplica & 0,17 & \\
\hline & & & & Sim & 0,21 & 0,21 \\
\hline & & & & Não & & 0,29 \\
\hline \multirow{3}{*}{ Deus } & 2 & 5,004 & $0,00^{* *}$ & Não se aplica & 0,05 & \\
\hline & & & & Não & & 0,24 \\
\hline & & & & Sim & & 0,31 \\
\hline \multirow{3}{*}{ Felicidade } & 2 & 3,733 & $0,02^{* *}$ & Sim & 0,09 & \\
\hline & & & & Não & 0,14 & 0,14 \\
\hline & & & & Não se aplica & & 0,16 \\
\hline \multirow[t]{3}{*}{ Missão } & 2 & 2,889 & $0,05^{*}$ & Não & 0,00 & \\
\hline & & & & Sim & 0,02 & 0,02 \\
\hline & & & & Não se aplica & & 0,03 \\
\hline \multirow{3}{*}{ Futuro } & 2 & 3,005 & $0,05^{*}$ & Sim & 0,00 & \\
\hline & & & & Não se aplica & 0,01 & \\
\hline & & & & Não & 0,01 & \\
\hline
\end{tabular}

* Significativo a nível de $\mathrm{p}<0,05$ * * Significativo a nível de $\mathrm{p}<0,001$. 
Por fim, verificaram-se eventuais diferenças entre as variáveis (sexo, trabalho, escolaridade) para a pergunta "para quem você dedica a vida". Em relação aos sexos, os resultados indicaram que as mulheres dedicam a vida para a 'família', enquanto os homens obtiveram maiores médias para'dedicar a vida para si'. Ao considerar as diferenças significativas entre pessoas que trabalham ou não, verificou-se que aqueles que não trabalham dedicam a vida à 'religião' e que as pessoas que trabalham dedicam 'ao outro'.

Quando as médias foram comparadas por escolaridade, pessoas com Ensino Médio diferenciaram-se dos de- mais grupos dedicando a vida à 'religião' e também com maiores pontuações na categoria 'família, religião, trabalho e estudos'. As pessoas com Pós-Graduação diferenciaram-se dos demais níveis de escolaridade com maiores médias para a categoria família quando comparada com pessoas com Ensino Médio ou Superior. A categoria "ao outro" também teve resultados significativos, porém, sem formação de subconjuntos na Prova de Tukey, embora com maiores médias para pessoas pós-graduadas. Ainda, a comparação das médias em função da prática religiosa resultou em diferenças significativas em seis categorias como apresentado na Tabela 6.

Tabela 6: Análise de variância e Tukey para a palavra associada a sentido de vida e prática da religião

\begin{tabular}{|c|c|c|c|c|c|c|c|}
\hline \multirow{2}{*}{ Variável } & \multirow{2}{*}{ gl } & \multirow{2}{*}{$\mathbf{F}$} & \multirow{2}{*}{$p$} & \multirow{2}{*}{ Prática da religião } & \multicolumn{3}{|c|}{ Subconjuntos } \\
\hline & & & & & 1 & 2 & 3 \\
\hline \multirow{3}{*}{ Família } & 2 & 6,532 & $<0,01^{*}$ & Não se aplica & 0,30 & & \\
\hline & & & & Sim & 0,35 & & \\
\hline & & & & Não & & 0,46 & \\
\hline \multirow{3}{*}{ Família, religião, trabalho e estudos } & 2 & 8,099 & $<0,01^{* *}$ & Não se aplica & 0,01 & & \\
\hline & & & & Não & 0,02 & & \\
\hline & & & & Sim & & 0,07 & \\
\hline \multirow{3}{*}{ Para si } & 2 & 13,927 & $<0,01^{* *}$ & Sim & 0,16 & & \\
\hline & & & & Não & & 0,26 & \\
\hline & & & & Não se aplica & & & 0,36 \\
\hline \multirow{3}{*}{ Religião } & 2 & 18,841 & $<0,01^{* *}$ & Não se aplica & 0,03 & & \\
\hline & & & & Não & 0,05 & & \\
\hline & & & & Sim & & 0,17 & \\
\hline \multirow{3}{*}{ Trabalho e estudo } & & 5,896 & $<0,01^{* *}$ & Não & 0,02 & & \\
\hline & & & & Sim & 0,03 & & \\
\hline & & & & Não se aplica & & 0,08 & \\
\hline
\end{tabular}

* * Significativo a nível de $\mathrm{p}<0,001$.

\section{Discussão e conclusão}

O presente estudo teve como objetivo identificar com o que os participantes mais associam o sentido de vida, a fim de melhor compreender o construto, ainda pouco mensurado (Schnell \& Becker, 2006), especialmente no Brasil (Oliveira \& Silva, 2013). Os resultados foram coletados em 25 estados brasileiros, além de contar com as respostas de brasileiros que moram em outros países. Embora não se tenha escolhido comparar as diferentes regiões por não ter a distribuição adequada e representativa de todas as unidades federativas, conseguiu-se uma amostra diversificada. Os resultados estão organizados em dois grupos, um primeiro que analisou as respostas mais frequentes nas três questões do instrumento, e um segundo, que visou comparar as categorias de respostas entre as variáveis sexo, trabalho, escolaridade e prática religiosa.

No que se refere às maiores frequências, a 'família' configurou como a primeira categoria na questão um (em que você tem depositado sua energia ultimamente), na segunda (para que ou quem você dedica sua vida) ou mesmo na terceira (quando eu digo para você sentido de vida qual a primeira palavra que você pensa imediatamente). Assim, pode-se afirmar que quanto à percepção da própria existência e em relação à busca do sentimento de realização existencial (Damasio, Melo, \& Silva, 2013), a família se destaca como associação mais presente. Ainda a este respeito, importante retomar as asserções de Sommerhalder (2010), no sentido de que apesar das experiências de vida serem singulares, elas fazem parte da cultura na qual a pessoa está inserida (Pereira, 2014).Nesse caso, famílias, filhos, pais e cônjuges foram identificados como os elementos principais do cotidiano dos pesquisados, o que permite reconhecer uma característica gregária, e que em alguma medida, reafirma os achados de Pinquart (2002), em sua meta-análise. $\mathrm{O}$ autor afirmou que diante de melhor integração social e pessoas casadas há maiores níveis de propósito de vida.

No que se refere ao segundo grupo de análises, foram encontradas diferenças entre os sexos nas três questões. As mulheres depositam sua energia na família, diferentemente dos homens que o fazem no trabalho, na paz e na 
liberdade. Quando questionados a que ou a quem dedicam suas vidas, as mulheres novamente se diferenciam dos homens na categoria 'família', enquanto eles se diferenciam delas no 'estudo'. As mulheres também se diferenciaram dos homens na categoria família, quanto à terceira questão, enquanto os homens se diferenciaram delas na categoria 'dedicar a vida para si'. A meta-análise de Pinquart (2002) e os achados de Ortiz e Morales (2013) concordaram ao afirmarem que as investigações quanto ao sentido na vida entre homens e mulheres não são unânimes. No entanto, no presente estudo, as diferenças entre os sexos foram claras especialmente na categoria 'família', com médias maiores para as mulheres nas três perguntas. Em outra medida, os homens tiveram médias maiores para aquelas categorias que indicam projetos mais individuais e autocentrados, que coletivos, como o trabalho, estudo e dedicar a vida para si mesmo.

A variável trabalhar ou não trabalhar revelou diferenças entre as categorias para a segunda e terceira questão, ou seja, quando os indivíduos eram levados a responder para que ou quem dedicam a vida ou a primeira palavra associada a sentido de vida. Em ambas as circunstâncias, as pessoas que não estão trabalhando diferenciaram-se significativamente daqueles que estão na ativa em duas categorias: futuro e religião. Por futuro, entende-se sentido de vida como praticar caridade e como algo a ser conquistado, o que pode ser considerado como uma característica positiva, e sob esta perspectiva, corrobora a pesquisa de Steger, Frazieret al. (2006). Os autores encontraram relação entre sentido de vida e aspectos positivos dos indivíduos. Também as pessoas que não trabalham citaram mais frequentemente a religião. Assim, estão mais disponíveis para caridade e religião os indivíduos não inseridos no mercado.

A escolaridade diferenciou categorias quanto às três perguntas. No entanto, os resultados não revelaram uma linha argumentativa lógica. Houve diferenças para os três níveis de ensino. Participantes com ensino médio endossaram mais as categorias 'religião' e a categoria mista 'família, religião, trabalho e estudos'. Por seu turno, os pós-graduados tiveram menores médias na categoria deus/fé', e maiores em 'amor' e 'família'. Embora alguns autores tenham identificado resultados favoráveis a determinados níveis educacionais (Claussen, \& Soto, 2015; Pinquart, 2002; Yuen \& Yau, 2015), presentemente não é possível fazer afirmações conclusivas.

Por fim, investigou-se como a religião diferenciaria nas categorias, sendo que os achados foram organizados em três categorias, aqueles que não possuem nenhuma crença; os que a possuem, mas não fazem parte de cultos ou quaisquer outras práticas; e os que a praticam. Para as duas primeiras perguntas, houve concordância quanto às diferenças significativas em relação à 'família', 'deus', 'felicidade', e a família também se fez presente na última questão. Quanto à 'família', houve diferença para quem não tem religião, em relação a quem a possui (praticantes ou não), sendo que os primeiros tiveram médias maiores para 'deus/fé' e quem pratica a religião teve média maior, significativamente diferente dos demais. Em relação ao fato, pode-se aventar que sentido de vida está associada à presença de outro, que no caso, pode ser materializada pela família ou mesmo pela fé (Damasio, Melo, \& Silva, 2013), de modo que ambos dariam suporte a essa construção existencial.

Duas últimas considerações devem ser destacadas; uma se refere à limitação quanto à composição da amostra, razão pela qual não se ousou realizar uma análise por unidades de federação, o que seria interessante, tendo em vista a característica do construto aqui estudado. Além disso, tratou-se de um artigo que investigou algumas variáveis. Seria interessante que idade, estado civil, nível socioeconômico, como exemplos, fossem também estudados, a título de agenda de pesquisa.

\section{Referências}

Allport, G. W. (1954). The roots of religion. Pastoral Psychology, 5 (43), 13-24.doi: 10.1007/BF01564726

Bardin, L. (2004). Análise de conteúdo. $3^{\circ}$. Lisboa: Edições, 70.

Claussen, M. V. C, \& Soto, V. M. D. (2015). Sentidos de vida de los universitários. Universidad Católica de Colombia, Educación y Educadores, 18 (3), 371-390. doi: 10.5294/ edu.2015.18.3.1.

Damásio, B. F. (2013). Sentido de vida e bem-estar subjetivo: interações com esperança, otimismo, autoeficácia e autoestima em diferentes etapas do ciclo vital (Tese de Doutorado), Universidade Federal do Rio Grande do Sul, Porto Alegre.

Damasio, B. F., Melo, R. L. P., \& Silva, J. P. (2013). Sentido de Vida, Bem-Estar Psicologico e Qualidade de Vida em Professores Escolares. Paidéia (Ribeirão Preto), 23 (54), 73-82. doi: 10.1590/1982-43272354201309.

Doğan, T., Sapmaz, F., Tel, F. T., Sapmaz, S., \& Temizel, S. (2012). Meaning in Life and Subjective Well-Being among Turkish University Students. Procedia - Social and Behavioral Sciences, 55, 612-617.doi:10.1016/j.sbspro.2012.09.543

Frankl, V. E. (1984). La idea psicológica del hombre (4. ed.). Madrid, España: Rialp.

Frankl, V. E. (1989). Psicoterapia e sentido da vida. São Paulo: Quadrante.

Frankl, V. E. (1993). A presença ignorada de Deus (3. ed.). Petrópolis, RJ: Vozes.

Frankl, V. E. (1998). Man alive: Viktor Frankl. The International Journal of Logotherapy and Existential Analysis, 6 (1), 81-96.

Halama, P. (2009). The Pil test in a Slovak sample: internal consistency and factor structure. International Forum for Logotherapy, 32, 84-88. Recuperado de: <http://katpsych. truni.sk/osobne/halama/PIL\%20slovak\%20I\%20F\%20Logotherapy.pdf $>$. 
Ho, M. Y., Cheung, F. M., \& Cheung, S. F. (2010). The role of meaning in life and optimism in promoting well-being. Personality and Individual Differences, 48, 658-663.doi: 10.1016/j. paid.2010.01.008

Kleiman, E. M., Adams, L. M., Kashdan, T. B., \& Riskind, J. H. (2013). Gratitude and grit indirectly reduce risk of suicidal ideations by enhancing meaning in life: Evidence for a mediated moderation model. Journal of Research in Personality, 47, 539-546. doi: 10.1016/j.jp. 2013.04.007

Maslow, A. H. (1962). Lessons from the peak-experiences. Journal of Humanistic Psychology, 2, 9-18.doi: 10.1177/002216786200200102.

Oliveira, E. K. S, \& Silva, J. P. (2013). Sentido de Vida e Envelhecimento: Relação entre os Pilares da Logoterapia e Bem Estar Psicológico. Revista da Associação Brasileira de Logoterapia e Análise Existencial, 2 (2), 135-146. Recuperado de: <http://periodicos.ufpb.br/ojs2/index.php/le/article/ view/16817/10100>

Ortiz, E. M., Cano, A. M. T., \& Trujillo, C. A. (2012). Validación del Test de Propósito Vital (Pil test purpose in life test) para Colombia. Revista Argentina de Clínica Psicológica, 21, 85-93. Recuperado de: <http://www.redalyc.org/articulo. oa?id $=281925884007>$.

Ortiz, E. M., \& C. C. Morales (2013). Percepción de sentido de vida em universitarios colombianos. Pensamiento Psicológico, 11 (1), 71-82. Recuperado de: <http://www.redalyc.org/ pdf/801/80127000009.pdf>.

Pereira, I, S. (2014). Consciência Moral Transcendente e Experiência Religiosa na Obra de Viktor Frankl. Teocomunicação (Porto Alegre), 44 (3), 418-432. Recuperado de: <http://revistaseletronicas.pucrs.br/ojs/index.php/teo/article/ view/19799/12555>.

Pinquart, M. (2002). Creating and Maintaining purpose in life in old age: A meta-analysis. Ageing International, Spring, 27 (2), 90-114. doi: 10.1007/s12126-002-1004-2

Schnell, T., \& Becker, P. (2006). Personality and meaning in life. Personality and Individual Differences, 41, 117-129. doi: 10.1016/j.paid.2005.11.030

Sommerhalder, C. (2010). Sentido de vida na fase adulta e velhice. Psicologia: Reflexão e Crítica, 23 (2), 270-277. doi:10.1590/S0102-79722010000200009

Steger, M. F., Frazier, P., Oishi, S., \& Kaler, M. (2006). The Meaning in Life Questionnaire: Assessing the presence of and search for meaning in life. Journal of Counseling Psychology, 53 (1), 80-93.doi: 10.1037/0022-0167.53.1.80.

Yuen, M., \& Yau, J. (2015). Relation of career adaptability to meaning in life and connectedness among adolescents in Hong Kong. Journal of Vocational Behavior, 91, 147-156. doi: 10.1016/j.jvb.2015.10.003.
Ana Paula Porto Noronha - Doutora em Psicologia: Ciência e Profissão pela Pontifícia Universidade Católica de Campinas. Docente do Programa de Pós-graduação Stricto Sensu em Psicologia da Universidade São Francisco. Bolsista Produtividade em Pesquisa - CNPq. Endereço Institucional: Rua Francisco Pinto Osório, 40, Jardim Morumbi, Itatiba - SP, CEP: 13.253-231. Email: ana.noronha8@gmail.com

Dianniffer Aparecida Oliveira - Psicóloga e Mestranda em Psicologia com ênfase em Avaliação Psicológica pela Universidade São Francisco. Email: diannifferoli@gmail.com

Leonardo de Oliveira Barros - Psicólogo, Mestre e Doutorando em Psicologia com ênfase em Avaliação Psicológica pela Universidade São Francisco (Bolsista CAPES). ÓRCID: 0000-0002-8406-0515

Thaline da Cunha Moreira - Psicóloga, Mestre e Doutoranda em Psicologia com ênfase em Avaliação Psicológica pela Universidade São Francisco (Bolsista CAPES).

Recebido em 25.11.2016 Primeira Decisão Editorial em 17.08.2017

Aceito em 31.08.2017 